\title{
La covid-19 en Cuba seis meses después*
}

\author{
Covid-19 in Cuba, six months later
}

\author{
Enrique Beldarraín \\ Chaple ${ }^{i}$ \\ ' Coordinador Área de Investigaciones, \\ Centro Nacional de Información de \\ Ciencias Médicas. \\ La Habana - Cuba \\ orcid.org/0000-0003-4448-8661 \\ ebch@infomed.sld.cu
}

Recebido em 25 set. 2020.

Aprovado em 29 set. 2020.
BELDARRAÍN CHAPLE, Enrique. La covid-19 en Cuba seis meses después. História, Ciências, Saúde - Manguinhos, Rio de Janeiro, v.28, n.4, out.-dez. 2021, p.1275-1280.

\section{Resumen}

Cuba tiene una larga tradición en el control de epidemias. En Cuba, se presentó la situación de la covid-19 seis meses después de su comienzo. Se tomaron medidas diferentes para controlar la pandemia: diversas intervenciones comunitarias, el aislamiento de contactos de casos sospechosos y de personas regresando del extranjero, la aplicación de estrategias terapéuticas. La primera fase epidémica tuvo un pico a finales de abril y en mayo presentó el mayor número de casos acumulados. Hubo un control de la epidemia en junio y julio. Se inició la desescalada a mediados de junio. Se constató un aumento de casos en el mes de agosto, que se interpreta como un rebrote de la misma.

Palabras clave: historia de covid-19; Cuba; epidemiología; control.

\section{Abstract}

Cuba has a long tradition of controlling epidemics. In Cuba, this occurred with covid-19 six months after it started. Different measures were taken to control the pandemic: various community interventions, the isolation of suspected cases and of people returning from overseas, the application of therapeutic strategies. The first phase of the epidemic peaked in late April and the highest number of cases was seen in May. The epidemic was under control in June and July. Cases began to de-escalate in mid-June. There was a rise in cases in the month of August, which was interpreted as another outbreak.

Keywords: history of covid-19; Cuba; epidemiology; control. 
$\mathrm{C}$ uba tiene una tradición en el trabajo de control de las enfermedades infectocontagiosas y epidemias. Ese trabajo fue iniciado, de forma consecuente, después de 1959, cuando la salud pública cubana cambió su orientación de curativa a preventiva y comenzaron las campañas de erradicación de enfermedades, como la campaña de lucha contra el paludismo, el mismo año 1959, siguieron las campañas de vacunación con el BCG, contra la difteria, la antitetánica hasta la campaña de vacunación antipolio, en 1962 (Delgado García, 1996; Beldarraín Chaple, 2005).

Vino después la instauración de los programas de control de enfermedades trasmisibles, estructuras verticales y permanentes, que tienen ya 57 años, establecidas en 1963, con la característica que son dinámicas, han cambiado, incorporando todos los adelantos científicos consolidados en cada momento (Beldarraín Chaple, 2005).

Un inestimable apoyo fue el desarrollo del área de educación sanitaria, que llevó a la comunidad mensajes para el cuidado de la salud de tal forma que poco a poco los empoderó con estos conocimientos redundando en una mejora de su estado de salud.

Experiencias en el control de epidemias importantes fueron las de fiebre tifoidea en los años 1960, las epidemias de dengue desde 1977, que generaron el diseño de campañas de lucha y posteriormente programas de control del vector de chikungunya y zika, y el cólera en el 2014.

Estos trabajos se hicieron posibles gracias al desarrollo, desde 1966, del subsistema de Higiene y Epidemiología, compuesto por una red de centros provinciales y municipales, sumados los laboratorios de microbiología y la voluntad política. Contó con el antecedente de los trabajos de los doctores Carlos J. Finlay, Juan Guiteras y de la Escuela Cubana de Sanitaristas (Beldarraín Chaple, 2020).

En el contexto de la actual pandemia de coronavirus SARS-CoV-2, los primeros casos de la covid-19 en Cuba se diagnosticaron el 11 de marzo del 2020 (Nota informativa..., 14 jun. 2020). El mundo contabilizaba 125.048 casos confirmados (6.729 nuevos de ese día) y 4.613 fallecidos (321 nuevos), abarcando un área de 118 países o territorios (WHO, 11 mar. 2020).

El presente artículo pretende reflexionar sobre el comportamiento de la covid-19 en Cuba y las medidas tomadas para su control. Para ello se revisaron las informaciones oficiales del Ministerio de Salud Pública (Minsap), artículos de prensa, así como artículos científicos publicados sobre el tema.

\section{Situación de la enfermedad hasta finales de agosto}

Los primeros días el aumento de los casos fue lento, entre el 11 y 31 de marzo se acumularon 212 casos positivos y seis fallecidos (Beldarraín Chaple et al., 2020), a partir de ese momento empiezan a incrementarse los casos constatándose la cifra mayor acumulada en mayo.

Pero el intenso trabajo multisectorial para contener la epidemia mostró que el pico ocurrió el 24 de abril, con 52 casos diagnosticados y 1.337 acumulados. Ese día fallecieron dos enfermos, totalizando 51, con 847 pacientes hospitalizados (Tabla 1, Figura 1) (Nota informativa..., 25 abr. 2020). 
Los fallecidos presentaron su máximo número en abril, después disminuyeron en mayo a menos de la mitad, y entre junio y finales de agosto solo ocurrieron 12, lo que ocasionó una disminución marcada de la letalidad (Tabla 1, Figura 2).

Se interpretó como causa de la baja incidencia de fallecidos el manejo que se tuvo desde el primer momento con las personas que fueron identificadas como sospechosas o que fueron contactos de casos confirmados o los que regresaban del extranjero. Sobre la comunidad en general, se efectuaron intervenciones profilácticas que incluyeron la realización de una pesquisa activa en la población para identificar posibles sospechosos o enfermos, los cuales se aíslaron. También se distribuyó un medicamento homeopático, el PrevengoVir, para autoadministración individual en los adultos, que levanta la inmunidad general. A grupos escogidos de población se le aplicó la vacuna antimeningocócica por sus efectos sobre el sistema inmunológico y a personas de la tercera edad, residentes en hogares de ancianos, tratamiento con Biomodulina $\mathrm{T}$.

En los Centros de Vigilancia de Viajeros, a quienes estuvieron expuestos a la enfermedad fuera del país, se les administró PrevengoVir y Factor de Transferencia, y Biomodulina T a los mayores de 60 años, que, si bien no evitan la enfermedad, pueden ayudar las personas que resulten contagiadas a enfrentarla. En los centros de Aislamiento de Contactos hay una vigilancia activa y en los Centros de Atención a Sospechosos ya se empieza un tratamiento que incluye los medicamentos Oseltamivir, Azitromicina, Interferón alfa2b.IM y EC/CIGB 2020, los dos últimos son productos de la biotecnología cubana (Redacción Minsap, 13 mayo 2020).

El objetivo de estas medidas ha sido vigilar y sacar de la comunidad a personas posibles afectadas y tomar acciones terapéuticas tempranas si desarrollan la enfermedad (Beldarraín Chaple et al., 2020).

Tabla 1: Casos diagnosticados y fallecidos por covid-19, letalidad, casos críticos y graves, muestras realizadas por mes (PCR), Cuba, 11.3.2020-31.8.2020

\begin{tabular}{ccccccccc}
\hline Meses & $\begin{array}{c}\text { Casos } \\
\text { positivos }\end{array}$ & $\begin{array}{c}\text { Casos } \\
\text { acumulados }\end{array}$ & Fallecidos & $\begin{array}{c}\text { Fallecidos } \\
\text { acumulados }\end{array}$ & Letalidad \% & $\begin{array}{c}\text { Casos } \\
\text { críticos }\end{array}$ & $\begin{array}{c}\text { Casos } \\
\text { graves }\end{array}$ & $\begin{array}{c}\text { N. de } \\
\text { muestras }\end{array}$ \\
\hline Marzo & 212 & 212 & 6 & 6 & 2,8 & - & - & 18.849 \\
Abril & 1.325 & 1.537 & 58 & 64 & 4,2 & 233 & 170 & 30.560 \\
Mayo & 546 & 2.083 & 19 & 83 & 4 & 59 & 145 & 57.383 \\
Junio & 265 & 2.348 & 3 & 86 & 3,7 & 12 & 55 & 66.116 \\
Julio & 285 & 2.633 & 1 & 87 & 3,3 & 8 & 32 & 94.586 \\
Agosto & 1.433 & 4.065 & 8 & 95 & 2,3 & 88 & 253 & 135.532 \\
\hline
\end{tabular}

Fuente: Ministerio de Salud Pública (Redacción Minsap, 18 sep. 2020). 


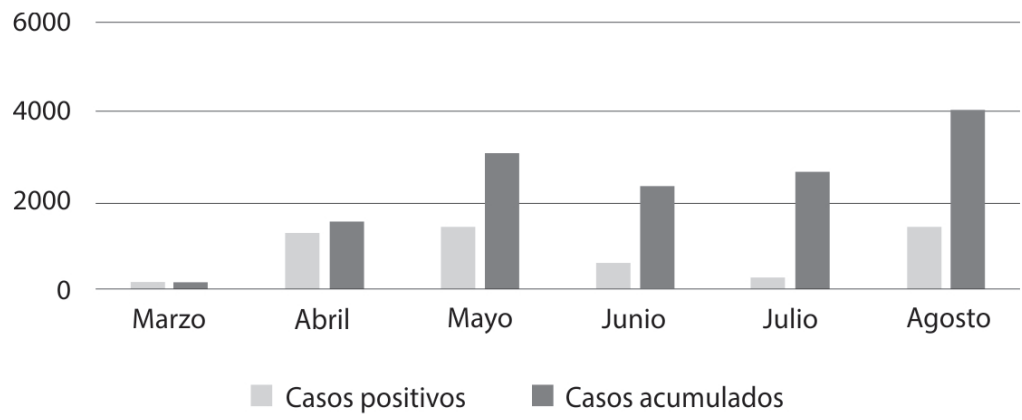

Figura 1: Casos diagnosticados con covid-19, Cuba, 11.6.2020-31-8-2020 (Fuente: Tabla 1)

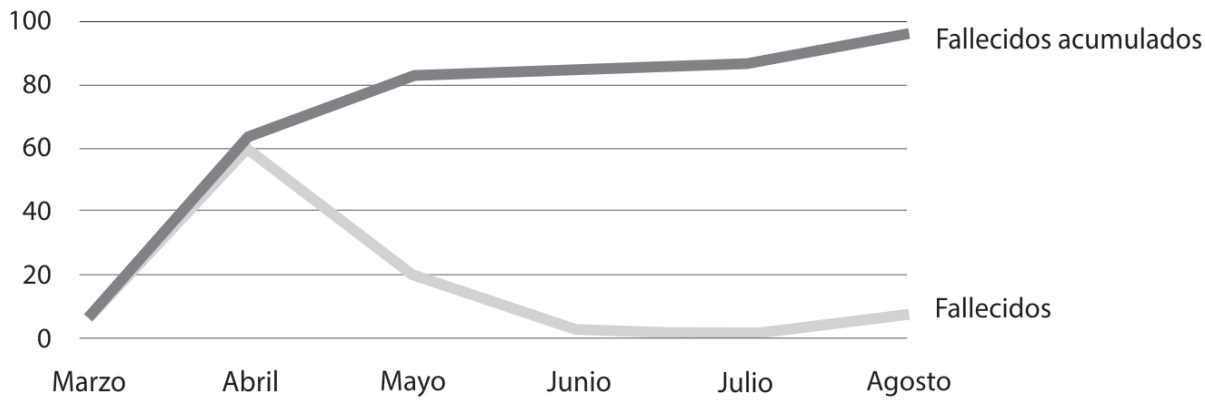

Figura 2: Casos fallecidos con covid-19, Cuba, 11.6.2020-31-8-2020 (Fuente: Tabla 1)

Entre el 24 de marzo y el 10 de abril se tomaron medidas de control y aislamiento: los residentes en el territorio nacional procedentes del extranjero pasaron a un régimen de aislamiento por 14 días. Con los visitantes extranjeros se reforzó la vigilancia en los hoteles, con dos evaluaciones diarias, que incluía también a los trabajadores. Se reforzó la vigilancia médica diaria en la población. Con el cierre de aeropuertos, terminales y estaciones de trenes se limitaron los servicios de transportación internacional e interprovinciales. Con esas medidas y la supresión temporal de la venta en los grandes centros comerciales se obligó a la comunidad a evitar lugares de aglomeración. Se tomaron medidas de aislamiento en zonas con eventos de transmisión local. Se restringió el movimiento de la población entre provincias y entre las zonas de las ciudades y de turismo. Se cerraron las escuelas y los centros de trabajo no imprescindibles, se potenció el teletrabajo y se llamó a la población al distanciamiento social y se determinó el uso obligatorio de mascarillas faciales (Beldarraín Chaple et al., 2020; Cuba frente..., 11 abr. 2020; Nota informativa..., 9 de mayo 2020).

Durante los meses de junio y julio se controló bastante el diagnóstico de nuevos casos de la enfermedad y la mortalidad fue muy escasa (Tabla 1). A partir del 18 de junio comenzó a aplicarse, de manera gradual, excepto en La Habana y Matanzas, una desescalada en tres fases. 
Estas dos provincias la iniciaron en julio. El pase a estas etapas dependió del cumplimiento de cinco indicadores sanitarios que evalúan el desarrollo de la epidemia en cada territorio: tasa de incidencia, índice reproductivo, casos activos, número de casos positivos con fuente de infección conocida en los últimos 15 días y eventos de trasmisión local.

Desde julio se constató indisciplina de la población en afluencias a playas y centros nocturnos, filas para comprar en tiendas, no cumplimiento del distanciamiento social y empezó el aumento nuevamente de los casos. La situación fue más compleja en las provincias de Artemisa, La Habana y Ciego de Ávila, observándose en el mes de agosto una cifra tan elevada de casos como en el mes de mayo, lo que se consideró un rebrote.

En esta segunda fase de la epidemia ocurren algunas diferencias con la anterior, entre ellas, la edad de los nuevos casos se ha movido hacia los jóvenes y niños, entre los cuales se han presentado mayor frecuencia de casos críticos y graves (Figura 3). Además se obligó a hacer más pruebas de PCR en la población (Tabla 1).

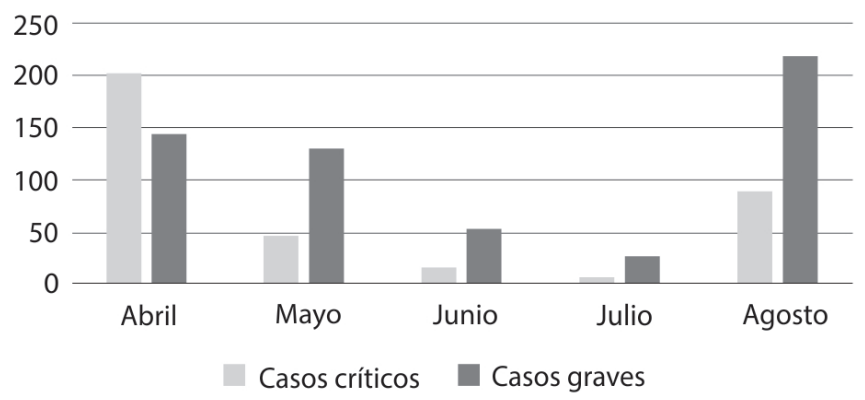

Figura 3: Casos críticos y graves por covid-19, Cuba, 11.3.2020-31.8.2020 (Fuente: Tabla 1)

En este período pandémico el Minsap dispuso cinco mil camas, con 472 de terapia intensiva para la atención médica relacionada con el coronavirus, en 20 hospitales acondicionados para ello, de los cuales se incluían seis de los siete hospitales militares con que cuenta el país, además de 54 centros para sospechosos, 248 de vigilancia de contactos y 40 para la atención a viajeros. Esto constituyó una fortaleza, pues estas facilidades permitieron alejar de la comunidad a las personas sospechosas y a los contactos de los casos positivos, ayudando a disminuir el número de contagios. Esto hizo una diferencia con muchos países del mundo, donde se presentó una gran crisis de instalaciones (Beldarraín Chaple et al., 2020).

En correspondencia con la situación, las autoridades decidieron suspender la desescalada en La Habana, retroceder a la fase de transmisión autóctona limitada. A partir del $1^{\circ}$ de septiembre del 2020, la entrada y salida desde la capital hacia otros territorios del país quedó suspendida. Lo mismo sucedió con el transporte público urbano. Además se restringió el movimiento de vehículos. El curso escolar no empezó, se insitió para volver al teletrabajo, se incrementó el aislamiento social, prohibió la salida de las personas y vehículos entre la siete de la noche y las cinco de la mañana.

A manera de conclusión, podemos considerar como fortalezas: la creación del Grupo Central del Estado (temporal), con reuniones diarias y toma de decisiones; la creación 
del Grupo de Ciencias, el desarrollo del protocolo de actuación (norma toda la conducta terapéutica preventiva y curativa), el establecimiento de una conducta de aislamiento (de sospechosos, contactos y pacientes) y la realización de estudios poblacionales.

Constituyen debilidades el hecho que todas las medidas no fueron lo suficientemente enérgicas en el momento oportuno y la indisciplina social de la población.

\section{NOTA}

* El siguiente texto es una versión más completa, actualizada y sometida a revisión de pares de un post que apareció en el blog de História, Ciências, Saúde - Manguinhos.

\section{REFERENCIAS}

BELDARRAÍN CHAPLE, Enrique. La Escuela Cubana de Sanitaristas valoración histórica en su centenario. Revista Cubana de Higiene y Epidemiología, 2020. Disponible en: http://www. revepidemiologia.sld.cu/index.php/hie/article/ view/347. Acceso en: 31 mar. 2021.

BELDARRAÍN CHAPLE, Enrique. Cambio y revolución: el surgimiento del Sistema Nacional Unico de Salud en Cuba, 1959-1970. Dynamis, v.25, p.257-278, 2005.

BELDARRAÍN CHAPLE, Enrique et al. Primer acercamiento histórico epidemiológico a la covid-19 en Cuba. Anales de la Academia de Ciencias de Cuba, v.10, n.2, especial covid-19, 2020. Disponible en: http://www.revistaccuba. cu/index.php/revacc/article/view/862/867. Acceso en: 31 mar. 2021.

CUBA FRENTE a la covid-19, día 32: últimas noticias. CubaDebate, 11 abr. 2020. Disponible en: http://www.cubadebate.cu/noticias/2020/04/11/ cuba-frente-a-la-covid-19-dia-32-ultimasnoticias/\#.XtfOiG5Fy3A. Acceso en: 8 jun. 2020.

DELGADO GARCÍA, Gregorio. Conferencias de historia de la administración de la salud pública en Cuba. Cuadernos Historia Salud Pública, n.81, p.18-26, 1996.

NOTA INFORMATIVA sobre la covid-19 en Cuba: 13 de junio. Infomed - Red de Salud de Cuba, Infecciones por coronavirus, 14 jun. 2020. Disponible en: https://temas.sld.cu/coronavirus/2020/06/14/notainformativa-sobre-la-covid-19-en-cuba-13-de-junio. Acceso en: 21 jun. 2020.
NOTA INFORMATIVA sobre la covid-19 en Cuba, 8 de mayo de 2020. Infomed - Red de Salud de Cuba, Infecciones por coronavirus, 9 mayo 2020. Disponible en: https://temas.sld. cu/coronavirus/2020/05/09/nota-informativasobre-la-covid-19-en-cuba-8-de-mayo. Acceso en: 8 mayo 2020 .

NOTA INFORMATIVA sobre la covid-19 en Cuba: 24 de abril. Infomed - Red de Salud de Cuba, Infecciones por coronavirus, 25 abr. 2020. Disponible en: https://temas.sld.cu/ coronavirus/2020/04/25/nota-informativasobre-la-covid-19-en-cuba-24-de-abril. Acceso en: 21 jun. 2020.

REDACCIÓN MINSAP. Parte de Cierre del día 17 de septiembre a las 12 de la noche, 18 sep. 2020. Disponible en: https://salud.msp.gob.cu/partede-cierre-del-dia-17-de-septiembre-a-las-12-dela-noche. Acceso en: 18 sep. 2020.

REDACCIÓN MINSAP. "El Sistema de Salud cubano" como tema de la Mesa Redonda, 13 mayo 2020. Disponible en: https://salud.msp. gob.cu/el-sistema-de-salud-cubano-como-temade-la-mesa-redonda. Acceso en: 13 ago. 2020.

WHO, World Health Organization. Coronavirus disease (COVID-19) Weekly Epidemiological Update and Weekly Operational Update. Coronavirus disease 2019 (covid-19), Situation Report 51, 11 mar. 2020. Disponible en: https:// www.who.int/docs/default-source/coronaviruse/ situation-reports/20200311-sitrep-51-covid-19. pdf?sfvrsn=1ba62e57_10. Acceso en: 15 abr. 2020.

\section{$\rightarrow \rightarrow \rightarrow<<<$}

